\title{
OPEN Inhibition of SYK and cSrc kinases can protect bone and cartilage in preclinical models of osteoarthritis and rheumatoid arthritis
}

\author{
F. N. Novikov ${ }^{1,2}$, M. V. Panova ${ }^{1}$, I.Y. Titov ${ }^{1,2 \bowtie}$, V. S. Stroylov ${ }^{1,2 \bowtie}$, O. V. Stroganov ${ }^{2,3}$ \& \\ G. G. Chilov ${ }^{2,3}$
}

The pathophysiology of osteoarthritis (OA) includes the destruction of subchondral bone tissue and inflammation of the synovium. Thus, an effective disease-modifying treatment should act on both of these pathogenetic components. It is known that cSrc kinase is involved in bone and cartilage remodeling, and SYK kinase is associated with the inflammatory component. Thus the aim of this study was to characterize the mechanism of action and efficacy of a small molecule multikinase inhibitor MT-SYK-03 targeting SYK and CSrc kinases among others in different in vitro and in vivo arthritis models. The selectivity of MT-SYK-03 kinase inhibition was assayed on a panel of 341 kinases. The compound was evaluated in a set of in vitro models of $O A$ and in vivo OA and RA models: surgically-induced arthritis (SIA), monosodium iodoacetate-induced arthritis (MIA), collagen-induced arthritis (CIA), adjuvant-induced arthritis (AIA). MT-SYK-03 inhibited CSrc and SYK with IC 50 $_{50}$ of.2 and $23 \mathrm{nM}$ respectively. Only five kinases were inhibited $>90 \%$ at $500 \mathrm{nM}$ of MT-SYK- 03 . In in vitro OA models MT-SYK- 03 reduced hypertrophic changes of chondrocytes, bone resorption, and inhibited SYK-mediated inflammatory signaling. MT-SYK- 03 showed preferential distribution to joint and bone tissue (in rats) and revealed disease-modifying activity in vivo by halving the depth of cartilage erosion in rat SIA model, and increasing the pain threshold in rat MIA model. Chondroprotective and antiresorptive effects were shown in a monotherapy regime and in combination with methotrexate (MTX) in murine and rat CIA models; an immune-mediated inflammation in rat AIA model was decreased. The obtained preclinical data support inhibition of CSrc and SYK as a viable strategy for disease-modifying treatment of OA. A Phase 2 clinical study of MT-SYK-03 is to be started.

Osteoarthritis (OA) is the most common musculoskeletal system disease causing incapacitation with frequency comparable to that for colds and viral diseases ${ }^{1-3}$. It manifests as joint inflammation and loss of joint function up to disability. Existing OA treatment options are associated with side effects ${ }^{4}$ and are directed towards symptomatic relief of pain and inflammation ${ }^{5}$. Thus, development of true disease-modifying osteoarthritis drugs (DMOADs) is urgently needed.

The pathogenesis of $\mathrm{OA}$ is associated with aberrant bone and cartilage tissue metabolism and the concomitant chronic inflammation ${ }^{6-8}$. Despite the molecular pathogenesis of OA is not clearly understood compared to self-antigen driven rheumatoid arthritis (RA), another chronic inflammatory disease affecting joints (as well as other tissues and organs), the role of cytokines such as IL-1b IL-6 and TNFa appears to be important in sustaining both conditions $\mathrm{s}^{9,10}$. Thus, inhibition of kinases downstream to the cytokines of interest might be a potential strategy for the OA treatment. One of the key kinases controlling cartilage and bone tissue remodeling is cSrc kinase $\mathrm{e}^{11-13}$. It is involved in a number of signaling cascades that induce hypertrophic changes in chondrocytes and lead to decrease in anabolic rate and acceleration of catabolic processes in cartilage. In addition, cSrc kinase

\footnotetext{
${ }^{1}$ Zelinsky Institute of Organic Chemistry RAS, 47 Leninsky Prospect, Moscow, Russian Federation 119991. ${ }^{2}$ National Research University Higher School of Economics (HSE), 20 Myasnitskaya Street, Moscow, Russian Federation 101000. ${ }^{3}$ Molecular Technologies, LLC, Moscow, Russian Federation. ${ }^{\square}$ email: il_tit@ bk.ru; victor.stroylov@gmail.com
} 
plays the key role in the formation of an actin ring, a unique element of the osteoclast cytoskeleton necessary for bone resorption ${ }^{13}$. Inhibition of cSrc kinase suppresses catabolism of cartilaginous tissue by inducing synthesis of essential articular cartilage components such as aggrecan and collagen II, reducing secretion of aggrecanases, and depressing osteoclast-mediated resorption of bone tissue ${ }^{14}$. Inflammation development during OA is associated with SYK kinase ${ }^{15-17}$, and leads to increased production of IL-1 $\beta$ and other inflammatory modulators which accelerate cartilage and bone tissue catabolism. SYK kinase inhibitors diminish the severity of inflammatory reaction ${ }^{18,19}$ and also decrease the rate of degenerative-dystrophic changes in the cartilaginous and bone tissues ${ }^{20,21}$.

Since both cSrc and SYK kinases are included in OA pathogenesis and are responsible for its catabolic and inflammatory effects, we hypothesize that their simultaneous inhibition can be used for developing diseasemodifying treatment of OA.

Here we report on the preclinical characterization of MT-SYK-03, a novel selective orally available kinase inhibitor with cSrc and SYK kinases among its main targets. MT-SYK-03 provides a tool for testing the hypothesis that simultaneous CSrc and SYK inhibition may be effective for disease-modifying OA treatment. We study the selectivity profile of MT-SYK-03 on a broad kinase panel (341 kinases) and assess its inhibitory activity in cellular assays. Furthermore, we test for efficacy of MT-SYK-03 in animal models of OA. Because OA and RA involve at least a number of common cytokines as well as some common clinical features (such as destruction of the barrier between the bone and cartilage ${ }^{22-24}$ and formation of a pannus ${ }^{25,26}$ ), the animal models of RA also considered in the current study. We conclude that simultaneous inhibition of cSrc and SYK by MT-SYK-03 is efficient in suppressing bone and cartilage destruction, as well as inflammation in in vivo models and can be nominated for further evaluation in clinical setting.

\section{Materials and methods}

All experiments were performed in accordance with relevant guidelines and regulations. The study was carried out in compliance with the ARRIVE guidelines.

MT-SYK-03 preparation. MT-SYK-03 was synthesized according to the reported procedure ${ }^{27}$.

In vitro experiments. SYK inhibition luminescent assay. Luminescent assay was performed at A. N. Bakh Institute of Biochemistry (Moscow, Russia). Recombinant 6xHis-SYK kinase (expressed in Sf9 cells) was obtained as described previously ${ }^{28}$. The reaction mixture containing the studied compound MT-SYK-03 or known SYK kinase inhibitor R406 ${ }^{19}$ as a reference $(1 \mathrm{nM}-10 \mu \mathrm{M})$ and $6 \mathrm{xHis}-\mathrm{SYK}(5 \mu \mathrm{L}, 0.7 \mathrm{pM})$ was incubated for $30 \mathrm{~min}$, then polyE4Y and ATP (up to $10 \mu \mathrm{M}$ ) were added. After incubation $(20 \mathrm{~min})$ Kinase-Glo reagent (Promega) was added. The luminescence was detected using the Fusion Universal Microplate Analyzer (PerkinElmer USA). The obtained $\mathrm{IC}_{50}$ values are given in Table S1, first column. Dose response curve of inhibitory activity of MT-SYK-03 against SYK kinase is presented in Fig. S1a.

SYK inhibition radiometric assay. Radiometric assay was performed at EMD Millipore Corporation (UK) by measuring the extent of substrate phosphorylation by 6xHis-SYK (expressed in Sf21 cells) using the standard protocol $^{29}$. The reaction mixture containing polyE4Y $(0.2 \mathrm{mg} / \mathrm{mL})$, GST-labeled kinase (up to $\left.2 \mathrm{nM}\right)$, the studied compound (MT-SYK-03 or R406) and ${ }^{32} \mathrm{P}$ ATP was incubated and spotted onto ion exchange filter; unbound phosphate was removed by extensive washing of filters in $0.75 \%$ phosphoric acid. The obtained $\mathrm{IC}_{50}$ values are given in Table S1.

cSrc inhibition and kinase selectivity profile assay. The activity of MT-SYK-03 against cSrc kinase and selectivity profile towards other 341 kinases was determined at Reaction Biology Corporation (Malvern, PA, USA) using the standard kinase assay protocol. The reaction mixture containing $0.1 \mathrm{mg} / \mathrm{mL}$ of substrate polyE4Y (Sigma, USA), 6xHis-SYK $(0.1-0.7 \mathrm{pM})$, the studied compound MT-SYK-03 or reference R406 (500 nM) and ${ }^{33} \mathrm{P}$ ATP (up to $10 \mu \mathrm{M}$, final specific activity $0.225-0.360 \mu \mathrm{Ci}$ ) was incubated $(120 \mathrm{~min}$ ) and spotted onto ion exchange filter; unbound phosphate was removed by extensive washing of filters in phosphoric acid. Kinase activity data was expressed as the percent remaining kinase activity in test samples compared to vehicle (dimethyl sulfoxide) reactions based on the radioactivity of reaction products (see Table S2). Experiment was replicated twice. $\mathrm{IC}_{50}$ values for kinase listed in Table S3 (having less than 50\% residual activity) were measured in 10-dose mode with threefold serial dilution starting at $10 \mu \mathrm{M}$ and curve fits were obtained using Prism4 Software (GraphPad). Dose response curve of inhibitory activity of MT-SYK-03 against cSrc kinase is presented in Fig. S1b.

In-vitro experiments. Osteoclast-mediated resorption of the mineralized matrix. The experiment was performed at Atlantic Bone Screen (France) and approved by Atlantic Bone Screen ethics committee. Human $\mathrm{CD} 14+$ monocytes were isolated from peripheral blood of healthy volunteers (informed consent was obtained from all subjects) using density gradient centrifugation (Ficoll-Hypaque) and magnetic cell sorting (MACS, MiltenyiBiotec). CD14 + monocytes $\left(1.5 \times 10^{6}\right.$ cells/well $)$ were cultured for three days in proliferation medium ( $a \mathrm{MEM} / \mathrm{FCS}-10 \%$ supplemented with $25 \mathrm{ng} / \mathrm{mL} \mathrm{M}-\mathrm{CSF}$ ), inducing proliferation and expression of RANK. Secondly, the cells were differentiated into osteoclasts in differentiation medium supplemented with $100 \mathrm{ng} / \mathrm{mL}$ RANKL for 4 days. Osteoclasts were detached from the wells using accutase, the cell suspension was homogenized and cells ( $75 \mu \mathrm{L} /$ well) were reseeded into: (a) a 96 -well plate coated with a synthetic mineralized matrix for an evaluation of osteoclast resorption, or (b) a classic 96-well plastic culture plate, for an assessment of osteoclast number. $75 \mu \mathrm{L}$ of differentiation medium containing M-CSF and RANKL (at a $2 \times$ concentration) was added to 
each well. The cells were incubated for an hour and were cultured for $48 \mathrm{~h}$ in the fresh differentiation medium supplemented with MT-SYK-03 or vehicle (DMSO, 0.3\%). All treatments were carried out in quadruple. Then the cell medium was removed, cells were lysed and the surface of the resorbed areas of the mineralized matrix was quantified in each well. TRAP staining was performed for cells in a classic plastic plate and the number of mature osteoclasts (TRAP-positive cells with three or more nuclei) was determined in each well. Reconstruction of images and osteoclast count was performed using Nikon NIS-D software. The obtained data are presented in Table S4.

Hypertrophic-like changes in IL-1 $\beta$ treated primary chondrocytes. The experiment was performed at Atlantic Bone Screen, France. To isolate primary chondrocytes, Sprague Dawley 3 weeks old rats were euthanized and their hind limbs were collected. Knee cartilage shavings were digested with collagenase in serum-free Dulbecco's Modified Eagle's Medium (DMEM). Once digested, the cell suspension was centrifuged and resuspended in DMEM containing $10 \%$ fetal bovine serum (FBS). Then the cells were plated on tissue culture plastic at a density of 10000 cells $\cdot \mathrm{cm}^{-2}$ and were amplified in monolayer in culture medium (DMEM/FCS-10\% supplemented with HEPES $(25 \mathrm{mM})$ ) until passage 1 and frozen at $-80^{\circ} \mathrm{C}$. Before study rat's chondrocytes were seeded and cultured in monolayers in 12-well plates for $24 \mathrm{~h}$. After that the cells were treated for three days with IL-1 $\beta(10 \mathrm{ng} / \mathrm{mL})$ and MT-SYK-03; positive (no treatment at all), negative (only IL- $1 \beta$ ) and vehicle (DMSO, $0.3 \%$ in cell medium) controls were also carried out in triplicate. At the end of the treatment, chondrocytes were lysed, and total RNA was purified using the NucleoSpin RNA II kit (Macherey Nagel). Total RNAs $(2 \mu \mathrm{g})$ were retro-transcribed using M-MLV RT (Lifetechnologies) and obtained cDNAs (10 ng) were used for qPCR to determine steady-state levels of type II collagen and aggrecan mRNAs (levels of RPL19 and $\beta$-actin mRNAs were used as controls). Each reaction was set up as follows: $5 \mu \mathrm{L}$ of iQ SYBR Green Supermix (Biorad, ref 1,708,882), $0.6 \mu \mathrm{L}$ of forward primer $(5 \mu \mathrm{M})$, and $0.6 \mu \mathrm{L}$ of reverse primer $(5 \mu \mathrm{M}), 1.8 \mu \mathrm{L} \mathrm{H} \mathrm{H}_{2} \mathrm{O}$, and $2 \mu \mathrm{L}$ of cDNA. All qPCRs (72 qPCRs per marker) were run on a DNA Engine Thermal Cycler Chromo 4 in triplicates and analyzed using REST software ${ }^{30}$. The obtained data are presented in Table S5.

Detection of SYK activity in cells by Western blot analyses. Western blot was performed at A. N. Bakh Institute of Biochemistry, Russia. Human B-cell lymphoma cells obtained from Russian collection cell cultures (RCCC) were cultured in 5\% CO2 humidified atmosphere at $37^{\circ} \mathrm{C}$ in RPMI 1640 supplemented with $100 \mathrm{U}$ $\mathrm{mL}^{-1}$ penicillin/streptomycin and $10 \%$ heat inactivated FBS. P3H3 cells $\left(10^{6}\right.$ cells in $1 \mathrm{ml}$ of RPMI media with $5 \%$ FBS) were incubated with test compound or vehicle control (DMSO, 1\%) for one hour at $37{ }^{\circ} \mathrm{C}$ in a $5 \%$ $\mathrm{CO}_{2}$-incubator. Then anti-IgM $(1 \mu \mathrm{g} / \mathrm{mL})$ was added to activate B-cell receptors and incubation continued for additional $15 \mathrm{~min}$. After that the cells were washed with cooled PBS buffer and were lysed in $200 \mu \mathrm{L}$ of ice-cold lysis buffer (62,5 mM Tris-HCl, pH 6.8, 2\% w/v SDS, 10\% glycerin, $50 \mathrm{mM} \mathrm{DTT,} 0,01 \% \mathrm{w} / \mathrm{v}$ BPB). Then lysates were sonicated for $20 \mathrm{~s}$ in ice, heated to $95-100^{\circ} \mathrm{C}$ for $5 \mathrm{~min}$ and centrifuged for $5 \mathrm{~min} .20 \mu \mathrm{L}$ of obtained samples were electrophoresed on 10\% SDS-polyacrylamide gel (gel blocks: $90 \times 60 \times 1.5 \mathrm{~mm}$; current intensity: $30 \mathrm{~mA}$, time: $2.5-3 \mathrm{~h}$ ) and transferred to nitrocellulose membranes (BioRad). Western blotting was carried out according to the Amersham Pharmacia Biotech ECL Western blotting protocol. After being blocked with nonfat milk (Valio, Finland) for one hour and washed, the membranes were incubated for one hour with corresponding primary antibody (SYK, p-SYK (Tyr352), p-SYK (Tyr525/526), p38, Jnk, Erk1/2, p-p38 (Thr180/Tyr182), p-Erk1/2 (Thr202/Tyr204), p-JNK (Thr183/Tyr185), BTK, p-BTK (Tyr223), CD19 and p-CD19 (Tyr531) antibodies (Cell Signaling Technology, USA)) in solution with 5\% BSA. The secondary antibodies were horseradish conjugated goat antirabbit antibodies.

B-cell activation in human whole blood. The whole blood assay was performed at N. N. Blokhin National Medical Research Center of Oncology (NMRCO), Russia and approved by NMRCO ethics committee. Informed consent was obtained from all subjects. Red blood cells were lysed by incubation with $\mathrm{NH}_{4} \mathrm{Cl}$ buffer $(0.8 \%$ $\mathrm{NH}_{4} \mathrm{Cl}$ and $0.1 \%$ EDTA in distilled water) for $5 \mathrm{~min}$ at $37^{\circ} \mathrm{C}$ and were precipitated by centrifugation (1500 rpm). The precipitates were resuspended in RPMI-1640 with $10 \%$ human serum and $2 \mathrm{mM}$ L-glutamine, after that the cells were again precipitated by analogous centrifugation and resuspended in RPMI-1640. Prepared B-cells were activated by incubation with anti-human IgD antibody (or $80 \mathrm{nM}$ PMA as a positive control) in presence of the test compounds (MT-SYK-03 or R406) or DMSO (5\%) for $16 \mathrm{~h}$ at $37{ }^{\circ} \mathrm{C}$ in $5 \% \mathrm{CO}_{2}$ humidified atmosphere. Blood was then stained directly with PE-conjugated anti-CD69 (dilution 1:10) and APC-conjugated anti-CD19 (dilution 1:20) antibodies for $20 \mathrm{~min}$ at $4{ }^{\circ} \mathrm{C}$. After that cells were precipitated by centrifugation $\left(1500 \mathrm{rpm}, 4^{\circ} \mathrm{C}\right.$ ) and washed twice with phosphate-buffered saline (PBS). The cells were resuspended in PBS containing $1 \%$ BSA and subjected to flow cytometry on BD FACS Canto II (BD Biosciences, USA). The number of active cells was estimated as a ratio of CD69-positive cells bearing a marker of CD19 cells, or as a mean fluorescence intensity (MFI) of CD69 + cells after gating on the CD19-positive cells. For dose-response curve see Fig. S2.

Inhibition of TNF- $\alpha$ secretion by activated monocytes. The assay was performed at A. N. Bakh Institute of Biochemistry, Russia. Human leukemia monocytic THP-1 cells obtained from Russian collection cell cultures (RCCC) were cultured in 5\% CO2 humidified atmosphere at $37^{\circ} \mathrm{C}$ in RPMI 1640 supplemented with $100 \mathrm{U}$ $\mathrm{mL}^{-1}$ penicillin/streptomycin, $2 \% \mathrm{FBS}$ and $20 \mu \mathrm{M} \beta$-mercaptoethanol. THP-1 cells were incubated in $5 \% \mathrm{CO}_{2}$ atmosphere at $37^{\circ} \mathrm{C}$ in RPMI 1640 medium. To induce differentiation the cells were treated with IFN-g for six days. 96-well culture plate coated with combined human IgG were incubated during night at $4{ }^{\circ} \mathrm{C}$ (or for $1 \mathrm{~h}$ at $37^{\circ} \mathrm{C}$ ). To evaluate baseline cell simulation $\left.\mathrm{F}(\mathrm{ab})_{2}\right)_{2}$ was used as a negative control in part of wells. Unbounded antibodies were removed with sodium-phosphate buffer. A solution of test compound (MT-SYK-03 or) and differentiated cells in cultivating medium were added in each well. The cells were incubated at $37^{\circ} \mathrm{C}$ after that the 
concentration of TNF- $\alpha$ in supernatant was measured fluorometrically using BMS223FF immunoanalytical kit by Bender MedSystems and $\mathrm{IC}_{50}$ value was computed. Each concentration was tested in triplicate; the experiment was replicated twice. For dose-response curve see Fig. S3.

In vivo experiments. Pharmacokinetics of MT-SYK-03 after single oral administration to rats and rabbits. Experiments were performed at ChemPartner, Shanghai, China and approved by Institutional Ethics Committee (IEC) of ChemPartner. Male Wistar 10-12 weeks old rats with body weights of 185-220 g and male New Zealand rabbits with body weights of 2.0-2.3 kg were purchased from Shanghai SLAC Laboratory Animal Co., Ltd. MT-SYK-03 was administered to the three groups of rats (six rats per group) via oral gavage at $10 \mathrm{~mL} /$ $\mathrm{kg}$ concentration, and in rabbits $5 \mathrm{~mL} / \mathrm{kg}$ concentration. Blood samples were kept on ice and centrifuged (2000 g, $4{ }^{\circ} \mathrm{C}, 5 \mathrm{~min}$ ) within $15 \mathrm{~min}$ post sampling.

Surgically induced meniscal tear $O A$ in rats. Medial meniscal tear (MMT) model was performed at Pharmenterprises, Russia according to the published procedure ${ }^{31}$ and approved by Ethics Committee of Pharmenterprises. Male 4-month old Sprague-Dowley rats were anesthetized with Zoletil (Vibrac, France) and Xylazine (Interchemie werken "De Adelaar" BV, Netherlands) mixture. The medial collateral ligament was transected, and the medial meniscus was grasped with a hemostat and reflected proximally toward the femur. The meniscus was transected and then skin was closed with sutures. 60-90 min after surgery rats were subcutaneously injected with flexoprofen (VIC GROUP, Russia). Treatment groups (20 rats each) were intragastrically treated with MTSYK-03 (100 and $500 \mathrm{mg} / \mathrm{kg}$ ) or vehicle control (0.5\% methylcellulose solution) $24 \mathrm{~h}$ before OA induction and then once daily for 21 day. Active control group was subcutaneously injected with zoledronic acid $(0.1 \mathrm{mg} / \mathrm{kg})$ $24 \mathrm{~h}$ before OA induction and then once every three days for 21 day. After 21 day animals were sacrificed; surgically operated right knee was removed and used for image analysis.

Monosodium iodoacetate induced osteoarthritis in rats. Monosodium iodoacetate (MIA) osteoarthritis model was performed at Pharmenterprises, Russia according to the known procedure ${ }^{32}$ and approved by Ethics Committee of Pharmenterprises. Male 10 week old Wistar rats were divided into eight groups: negative control (\#1), positive control (\#2) and six treatment groups (\#3-8), ten rats in each group. Group \#1 was left intact while rats in groups \#2-8 were anesthetized on the day 0 with intraperitoneal injection of Zoletil and Xylazine mixture and given a single intra-articular injection of MIA through the infrapatellar ligament of the right knee. Rats were treated as follows: (\#1, \#2) $0.5 \%$ solution of methylcellulose in PBS (pH=3) as vehicle control, (\#3, \#5) $100 \mathrm{mg} / \mathrm{kg}$ MT-SYK-03, (\#4,\#6) $500 \mathrm{mg} / \mathrm{kg}$ MT-SYK-03, (\#7) $50 \mathrm{mg} / \mathrm{kg}$ nalgesin and (\#8) $0.1 \mathrm{mg} / \mathrm{kg}$ zoledronic acid. Rats in groups \# 1-4 received treatment intragastrically QD, 25 and $1 \mathrm{~h}$ before the MIA injection, and then daily until the end of the study on the day 28. Rats in groups \#5-6 received treatment intragastrically QD from the day 7 until the end of the study. Rats in group \#7 were treated QD starting on the day 14 and until the end of the study. Finally, rats in group \#8 were treated subcutaneously immediately after the MIA injection and then every third day until the study end. Disease progression was monitored by measuring mechanical hyperalgesia, mechanical allodynia and grip strength of hind paws on the days 14,21 , and 28, just before the treatment, and 1, 3, $6 \mathrm{~h}$ after it.

For experimental details on Collagen-Induced Arthritis and Adjuvant-Induced Arthritis please refer to the Supplementary Material.

\section{Results}

MT-SYK-03 is a potent and selective cSrc/SYK kinases inhibitor. MT-SYK-03 inhibited activities of cSrc and SYK kinases potently with $\mathrm{IC}_{50}$ values of $23-40 \mathrm{nM}$ and $14 \mathrm{nM}$, correspondingly (Fig. 1). Of the other 341 protein kinases tested, at $500 \mathrm{nM} 34$ kinases were inhibited by more than 50\%, 13 kinases-by more than $80 \%$ and only five kinases by more than $90 \%$ (DDR1, YES1, MAP3K10, LYN, BLK). Some of these kinases were found to be associated with osteoarthritis. DDR1 is expressed in chondrocytes, and is known to bind to type I collagen $^{33}$; activates p38, ERK1/2, JNK MAP и PI3-AKT signal pathways ${ }^{34,35}$, as well as the Wnt/ $\beta$-catenin one ${ }^{36}$. Osteoarthritis of temporomandibular joint was shown to develop spontaneously in Ddr1 $1^{-/-}$mice $^{37}$. DDR1 was also recently shown to be involved in periostin-associated elevated MMP-13 expression via an AKT-Wnt/ $\beta$ catenin pathway ${ }^{38}$. However, it is questionable that inhibition of Ddr1 kinase alone can have clinical effect on OA, because Ddr1 kinase is a common off-target of many approved kinase inhibitors, particularly approved Bcr-Abl inhibitors (imatinib, dasatinib, nilotinib, ponatinib), for which no data on efficacy in OA was reported. MAP3K10 is known to regulate cytokine expression, support homeostasis and regulatory T-cell functions in rheumatoid arthritis pathogenesis ${ }^{39}$; involved in Jnk and Jun mediated signaling pathways and has potential implications in osteoporosis pathogenesis ${ }^{40}$. Polymorphisms in BLK are potentially associated with increased risk of rheumatoid arthritis (RA) ${ }^{41}$.

A known SYK kinase inhibitor R406 was found to be less selective in the same assay: it inhibited 104 kinases by $>50 \%, 50$ kinases by $>80 \%$ and 26 kinases by $>90 \%$.

MT-SYK-03 effectively suppresses osteoclast-mediated bone resorption and inhibits degradation of aggrecan and type II collagen in chondrocytes. In the human osteoclast resorption assay MT-SYK-03 dose-dependently inhibited osteoclast resorption, reducing the relative resorbed surface more than threefold at $10 \mu \mathrm{M}$ (Fig. 2). Anti-hypertrophic effect of MT-SYK-03 was assessed in chondrocytes treated with IL- $1 \beta$ where MT-SYK-03 increased the gene expression levels of aggrecan and type II collagen (Table S5). The increase in aggrecan expression was dose-dependent (Fig. S12). 
a<smiles>COc1cc(Nc2ncnc(Nc3cc4c(cn3)NC(=O)C(C)(C)O4)n2)cc(OC)c1OC</smiles>

$b$

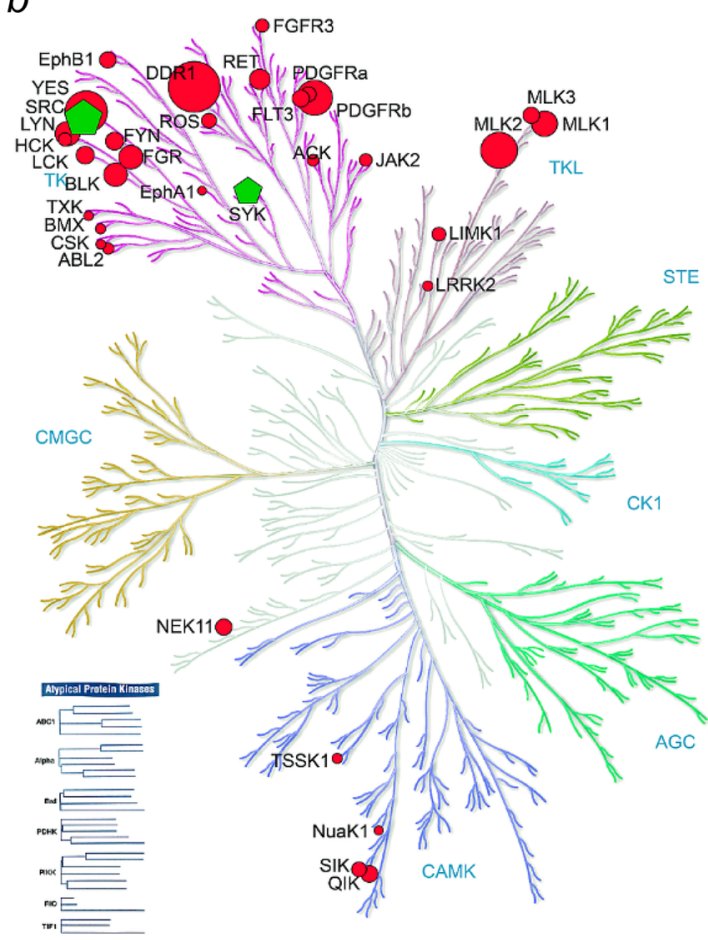

$C$

\begin{tabular}{cc} 
Kinase & IC50, nM \\
\hline CSrC & 14 \\
SYK & $23-40$ \\
\hline Kinase & IC50, nM \\
DDR1 & 1.8 \\
YES/YES1 & 3.5 \\
MLK2/MAP3K10 & 4.3 \\
LYN & 8.8 \\
BLK & 9.6 \\
LCK & 20 \\
FLT3 & 23 \\
SIK2 & 23 \\
EPHB1 & 25 \\
SIK1 & 36 \\
LIMK1 & 45 \\
ACK1 & 86 \\
BMX/ETK & 199
\end{tabular}

Figure 1. (a) Chemical structure of MT-SYK-03. (b) Kinase profiling of MT-SYK-03 (500 nM) against 343 kinases. Circle size on dendrogram is proportional to percentage of kinase residual activity: big circles, $<10 \%$ activity; small circles, $<20 \%$ activity. Green pentagons represent SYK and cSrc kinases. Kinase dendrogram background taken from Manning et al. Science 298 (2002). Reprinted with permission from AAAS. (c) IC $_{50}$ values for $\mathrm{cSrc}$ and SYK kinases and other kinases with residual activity at $500 \mathrm{nM}$ MT-SYK-03 below $20 \%$.

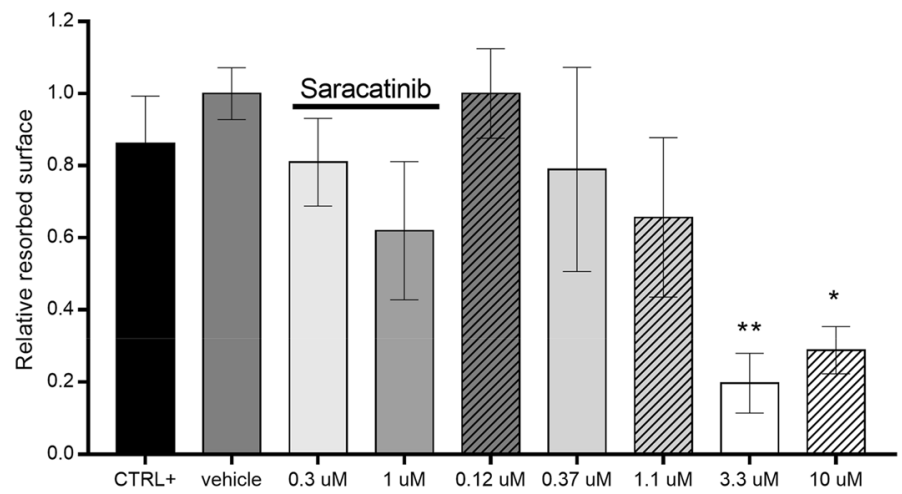

Figure 2. Relative resorbed surface after treatment with MT-SYK-03. The percentage of resorbed surface relative to the mean number of osteoclasts was calculated and compared to the vehicle control. Data are expressed as mean relative resorption $\pm \mathrm{SD}\left({ }^{*} \mathrm{p}<0.05 ;{ }^{* *} \mathrm{p}<0.01\right)$ using Kruskal Wallis and Dunnet's post test. 


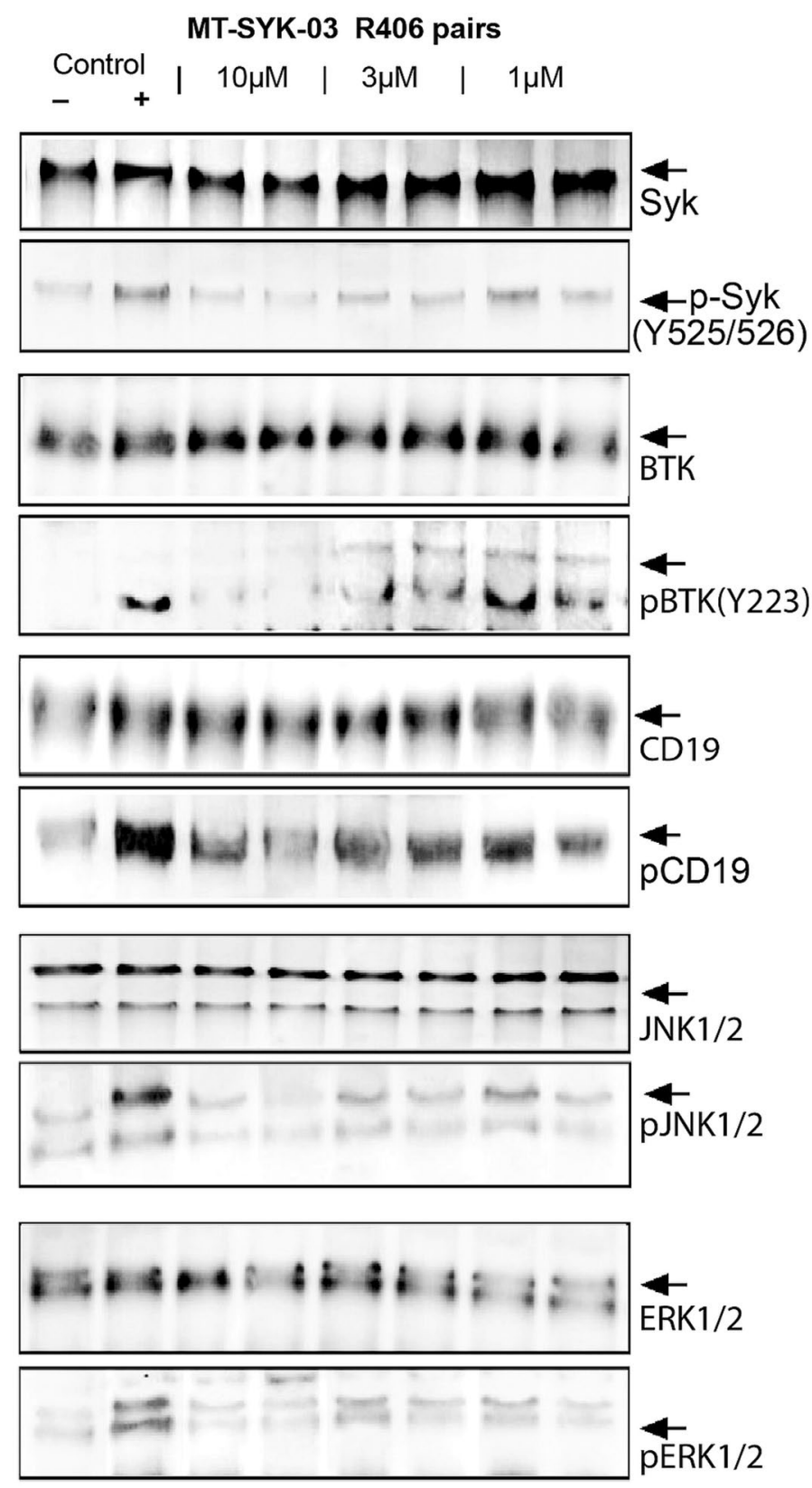

Figure 3. Effect of the MT-SYK-03 and a reference compound (R406, right hand side of each pair) on phosphorylation of the main modulators of the B-cell cascade development (tyrosine kinases Syk, BTK, as well as CD19 receptor) and effector kinases of mitogen/stress-activated signal cascade (JNK1/2 and ERK1/2). Cropped image from different blots is presented, as indicated by borders. Each section corresponds to a different blot.

MT-SYK-03 inhibits SYK-mediated signaling. Inhibition of SYK activity correlates well with suppression of B-cell activation. Treatment with MT-SYK-03 dose-dependently inhibited anti-IgM induced autophosphorylation of SYK kinase, phosphorylation of downstream B-cell signaling cascade components CD19 and BTK, as well as components of MAP cascade (ERK1/2 and JNK1/2) (Fig. 3).

SYK-kinase mediated inflammation induction can be achieved through B-cell receptor signaling and inflammatory cytokines production via Fc $\gamma \mathrm{R}$ signaling ${ }^{42}$. To confirm inhibition of SYK-dependent B-cells activation in human whole blood it was stimulated with anti-IgD (anti-BCR) or PMA to induce SYK-dependent or SYKindependent activation of B cells. Thus, MT-SYK-03 inhibited BCR-dependent (but not PMA-dependent) activation of B cells with $\mathrm{IC}_{50}$ value of $0.550 \mu \mathrm{M}$ (Fig. S2).

As SYK kinase is also a key participant in Fc $\gamma$ R-dependent signaling in monocytes, MT-SYK-03 effect was evaluated in the model of inhibition of cytokines production by differentiated monocytes. A dose-dependent inhibition of TNF- $\alpha$ release with $\mathrm{IC}_{50}$ value of $0.48 \mu \mathrm{M}$ (Fig. S3) was shown. This effect of MT-SYK-03 may 


\begin{tabular}{|c|c|c|c|c|}
\hline \multirow[b]{2}{*}{ Parameters } & \multicolumn{3}{|l|}{ Rats } & \multirow{2}{*}{\begin{tabular}{|l|} 
Rabbits \\
$50 \mathrm{mg} / \mathrm{kg}$
\end{tabular}} \\
\hline & $30 \mathrm{mg} / \mathrm{kg}$ & $100 \mathrm{mg} / \mathrm{kg}$ & $200 \mathrm{mg} / \mathrm{kg}$ & \\
\hline $\mathrm{T}_{\max }, \mathrm{h}$ & $1.5 \pm 0.548$ & $1.0 \pm 0$ & $1.33 \pm 0.516$ & $6.00 \pm 2.19$ \\
\hline$C_{\max }, \mathrm{ng} / \mathrm{mL}$ & $416 \pm 114$ & $864 \pm 89.4$ & $1276 \pm 160$ & $8573 \pm 2893$ \\
\hline$C_{\max }, \mathrm{nM}$ & $684 \pm 187$ & $1424 \pm 147$ & $2099 \pm 263$ & $14,102 \pm 4759$ \\
\hline$\tau_{1 / 2}, \mathrm{~h}$ & $5.53 \pm 2.38$ & $4.06 \pm 1.49$ & $5.08 \pm 2.39$ & $7.41 \pm 1.32$ \\
\hline $\mathrm{AUC}_{48}, \mathrm{~h} \cdot \mathrm{ng} / \mathrm{mL}$ & $2339 \pm 979$ & $4260 \pm 621$ & $7274 \pm 1490$ & $119,493 \pm 39,753$ \\
\hline $\mathrm{AUC}_{\text {inf }}, \mathrm{h} \cdot \mathrm{ng} / \mathrm{mL}$ & $2418 \pm 945$ & $4273 \pm 608$ & $7319 \pm 1458$ & $120,951 \pm 39,331$ \\
\hline $\mathrm{Kel}, \mathrm{h}^{-1}$ & $0.16 \pm 0.09$ & $0.19 \pm 0.08$ & $0.17 \pm 0.09$ & $0.096 \pm 0.015$ \\
\hline $\mathrm{MRT}_{24}, \mathrm{~h}$ & $4.26 \pm 0.57$ & $4.12 \pm 0.56$ & $4.89 \pm 1.63$ & $9.2 \pm 0.66$ \\
\hline
\end{tabular}

Table 1. The main pharmacokinetic parameters after oral MT-SYK-03 administration in rats in three single doses and rabbits.

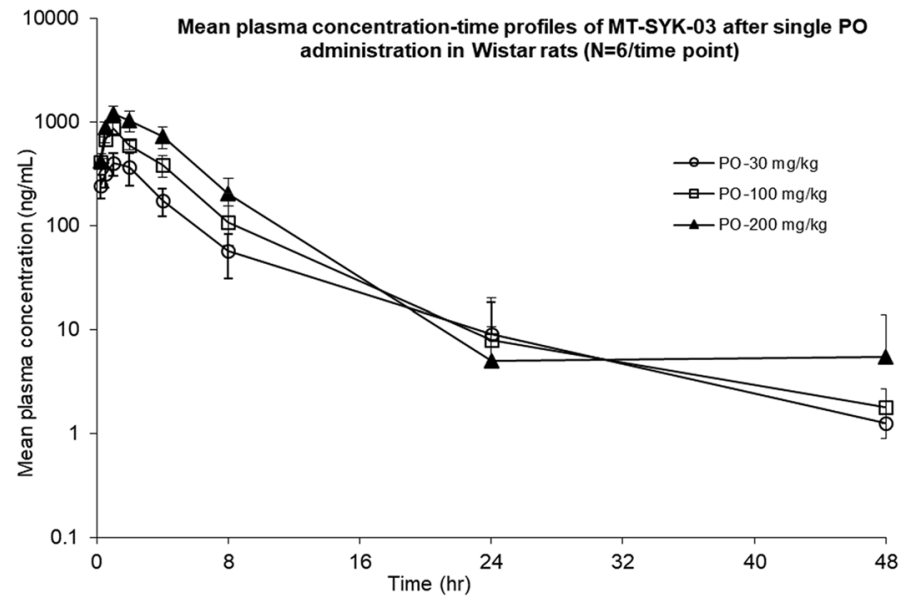

Figure 4. Mean plasma concentration-time profiles of MT-SYK-03 after PO administration of $30 \mathrm{mg} / \mathrm{kg}$ (circles), $100 \mathrm{mg} / \mathrm{kg}$ (squares) and $200 \mathrm{mg} / \mathrm{kg}$ (triangles) in male Wistar rats ( $\mathrm{N}=6 /$ time point).

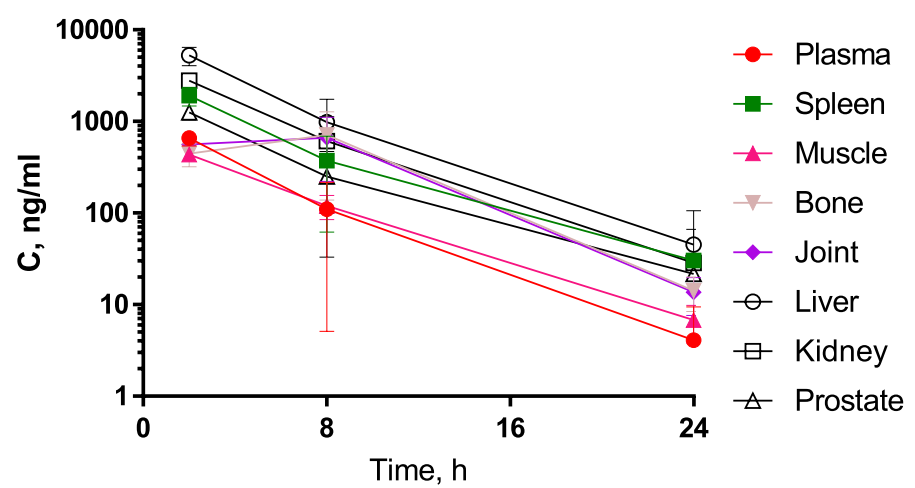

Figure 5. The dynamics of MT-SYK-03 concentration in various tissues after a single oral administration in rats.

potentially translate into inhibition of TNF- $\alpha$-induced inflammation and destruction of the joint cartilage during $\mathrm{OA}^{43,44}$.

MT-SYK-03 pharmacokinetics profile and distribution in rats and rabbits. The pharmacokinetic parameters after single oral administration of MT-SYK-03 are presented in Table 1 and Figs. 4 and 5. AUC and $\mathrm{C}_{\max }$ were dose-proportional, $\mathrm{T}_{\max }$ and $\mathrm{t}_{1 / 2}$ were dose-independent. The exposure to MT-SYK-03 was threefold higher in target tissues (bone and cartilage) than in plasma (Fig. 5). In rabbits the compound reaches higher plasma concentrations compared to rats. 
a

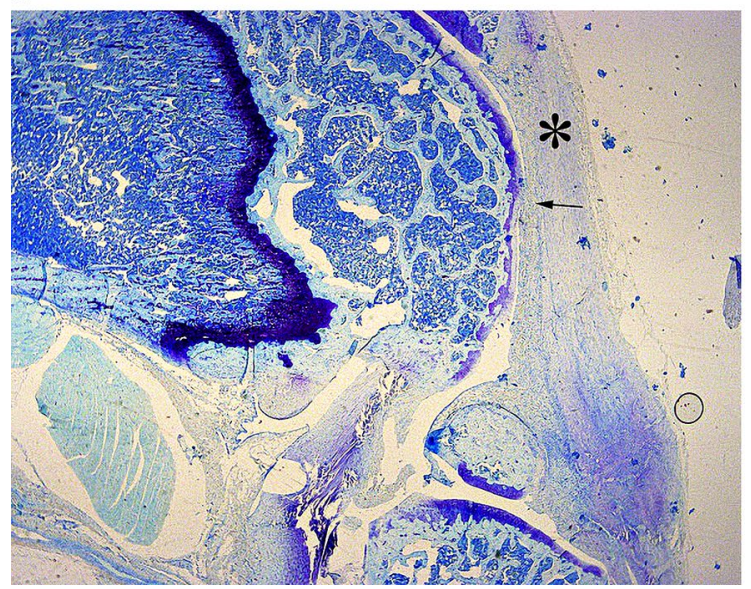

$b$

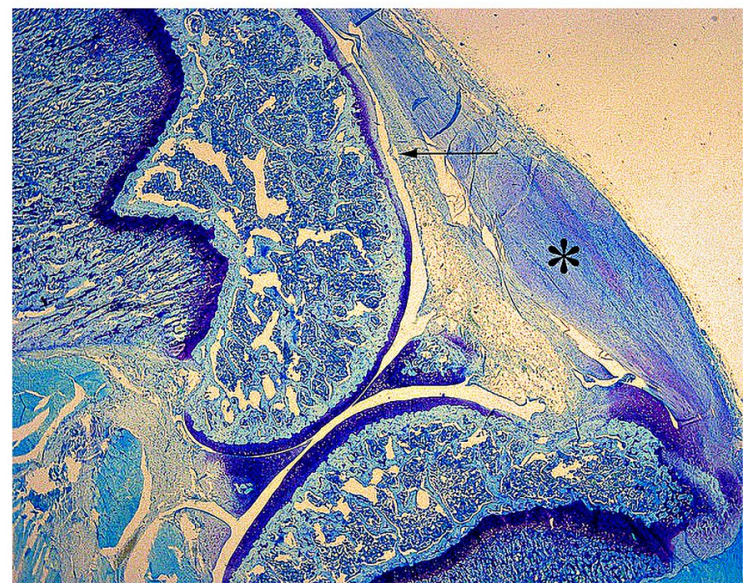

Figure 6. MT-SYK-03 protects against cartilage damage after medial meniscal tear in rats. Photomicrographs of sagittal cross Sects. (10 × magnification) of knee 21 days after medial meniscal tear surgery are shown for: (a) vehicle group; (b) treatment with MT-SYK-03 (500 mg/kg) group. Arrows indicate erosions, asterisks indicate thickening of the joint capsule.

\begin{tabular}{|l|l|l|}
\hline Group & Lesion depth, \% & Lesion area, \% \\
\hline Intact & $0 \pm 0$ & $0 \pm 0$ \\
\hline Control & $68.5 \pm 6.7$ & $37.0 \pm 4.2$ \\
\hline MT-SYK-03 $(100 \mathrm{mg} / \mathrm{kg})$ & $72.5 \pm 6.0$ & $37.3 \pm 3.3$ \\
\hline MT-SYK-03 $(500 \mathrm{mg} / \mathrm{kg})$ & $35.0 \pm 3.0 \&$ & $30.5 \pm 2.8$ \\
\hline zoledronic acid & $50.5 \pm 7.1$ & $25.3 \pm 2.2^{\text {\& }}$ \\
\hline
\end{tabular}

Table 2. The area and surface of a lesion of cartilage tissue after meniscectomy on day $21 .{ }^{*}$ Statistically significant $(\mathrm{p}<0.05)$ compared with the control group.

MT-SYK-03 shows anti-resorptive effects on cartilage in surgically induced meniscal tear OA in rats. The most commonly used rat medial meniscal tear (MMT) model demonstrates cartilage destruction and dynamic subchondral bone changes. Therefore, the cartilage- and bone-preserving activities of therapeutic agents can be evaluated in this model ${ }^{45}$. The model was carried out for 21 day, before gross joint damage becomes evident ${ }^{46}$ : moderate to severe knee $\mathrm{OA}$ is already a late stage of the disease with advanced tissue changes that may not be amenable to any drug aimed at modifying the disease course ${ }^{4}$. It was shown that using disease-modifying OA therapy as a benchmark, that a positive result in rat MMT model would be predictive of efficacy in human $\mathrm{OA}^{47}$. We compared MT-SYK-03 with zoledronic acid. Joint damage was assessed histologically 3 weeks after surgery. Animals treated with vehicle were characterized by thickening of the joint capsule (fibrosis and hyperplasia of the synovial membrane) and erosion of the articular surfaces, down to the lower part of the cartilage (Fig. 6a). MT-SYK-03 therapy (500 mg/kg) halved lesion depth (from $68.5 \pm 6.7 \%$ in vehicle group to $35.0 \pm 3.0 \%$ in treatment group) (Fig. 6b). Treatment with zoledronic acid reduced lesion depth to a lesser extent. Lesion area was also smaller for both MT-SYK-03 and zoledronic acid treatment compared to negative control (Table 2).

MT-SYK-03 is effective in mouse collagen-induced arthritis model. Collagen-induced arthritis (CIA) model can be used to study all three components (cartilage and bone destruction as well as inflammation) of arthritis pathogenesis ${ }^{48}$. During the CIA development, paw inflammation was evident within 26 to 27 days after antigen boosting, at which time oral administration of MT-SYK-03 was initiated. MT-SYK-03 exhibited chondroprotective and antiresorptive effectiveness even at low dose $(103 \mathrm{mg} / \mathrm{kg})$ : microphotographs of knees (Fig. 7) indicate decreasing of cartilage damage, bone resorption and inflammation in knees.

These results are consistent with decreased histopathology scores for knee and ankle joints for animal treated with MT-SYK-03. In case of a combination therapy with methotrexate (frequently used as reference ${ }^{49,50}$ ) these results were statistically significant (Fig. S16). MT-SYK-03 slightly decreased periosteal bone width of paw and knee joints. This effect was statistically significant when MT-SYK-03 was used in combination with MTX (Fig. S17, Table S18).

As for anti-inflammatory activity, MT-SYK-03 at $103 \mathrm{mg} / \mathrm{kg}$ reduced the severity of inflammation (Fig. 8a). The effect was larger when combined with MTX $(1.5 \mathrm{mg} / \mathrm{kg})$. Reduction of inflammation was more pronounced if measured by only non-involved paws (Fig. 8b), suggesting the autoimmune contribution. 

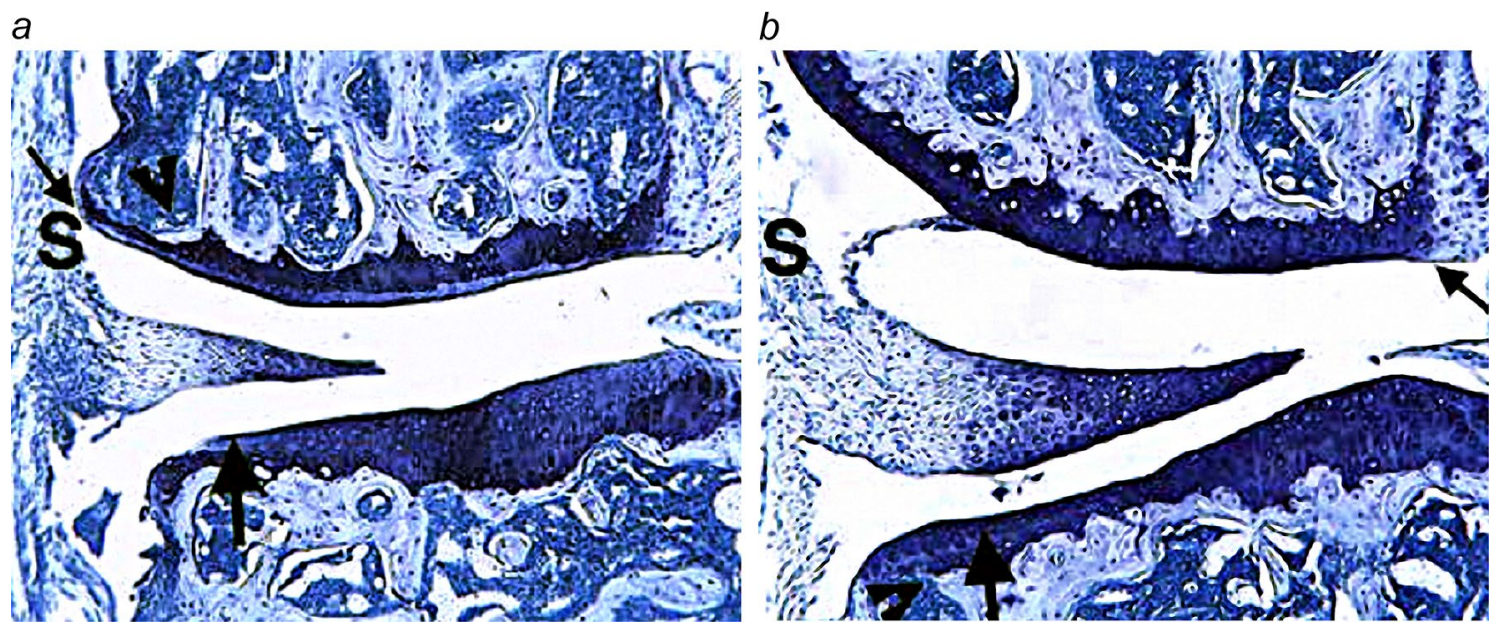

Figure 7. MT-SYK-03 alleviates inflammation and cartilage damage in murine CIA. Frontal section, $100 \times$ magnification. $a$. The knee from a vehicle control animal reveals moderate inflammation $(S)$ and marked cartilage damage (large arrow) with very minimal pannus (small arrow) and bone resorption (arrowhead). $b$. The knee from an arthritic animal treated with $103 \mathrm{mg} / \mathrm{kg}$ of MT-SYK-03 has very minimal inflammation (S) and minimal cartilage damage (large arrow).

MT-SYK-03 is effective in rat collagen-induced arthritis model. In the rat CIA model, treatment was initiated on study day 6, 5-6 days before the ankle inflammation began (Fig. S9). As pharmacokinetics studies in rats showed fast metabolism of MT-SYK-03 with $\tau_{1 / 2}$ value of $5.08 \pm 2.39 \mathrm{~h}$ at $200 \mathrm{mg} / \mathrm{kg}$ dose (Table 1), higher doses of MT-SYK-03 (compared to murine CIA model) were used in this experiment. Blinded histopathology scores for cartilage damage and bone resorption (Fig. 9, see SI for scoring details) indicated that MTSYK-03 demonstrated chondroprotective and antiresorptive effects, although statistical significance was reached only for the knee bone resorption. MTX alone did not show statistical significance for any parameter, however its combination with $103 \mathrm{mg} / \mathrm{kg}$ of MT-SYK-03 was found to have statistically significant effects on all disease progression parameters, both at knees and ankles (Fig. 9).

Measurements of periosteal bone width (Fig. 9c) showed that high-dose MT-SYK-03 (207 mg/kg) and MTX similarly decrease periosteal bone formation by $\sim 43 \%$, while combination of the latter with low dose of MTSYK-03 resulted in stronger decrease of $\sim 68 \%$.

Histopathology scores of inflammation and pannus formation were also smaller for MT-SYK-03 (207 mg/kg). For a combination of $103 \mathrm{mg} / \mathrm{kg}$ MT-SYK-03 with MTX the changes were statistically significant. As opposed to treatment with MT-SYK- 03 or MTX alone, the combination yielded the largest effect (10\% diameter reduction) which stayed statistically significant from day 11 up to the end of the study, and resulted in statistically significant $56 \%$ paw weight reduction at the study end (Figs. S9, S10). Relative weights of thymus, liver and spleen were statistically identical across all groups (Fig. S11), indicating absence of toxic effects of MT-SYK-03 treatment.

MT-SYK-03 shows anti-inflammatory effect in adjuvant-induced OA in rats. Primary and secondary immunological reactions to the adjuvant injection were assessed by measuring volumes of the involved (CFA-injected) and non-involved paws, respectively, on days 0, 14, 18, 21, 25, and 28. MT-SYK-03 in doses 103 and $207 \mathrm{mg} / \mathrm{kg}$ and high-dose MTX decreased the volume of non-involved paws on the day 28, while diclofenac and low-dose MTX showed no statistically significant effect compared to control animals (Table S26). Combinations of MTX with MT-SYK-03 have shown statistically significant reduction of volume of paws on the days 21, 25 and 28.

Considering the treated paws (Table S22), only MTX and its combinations with MT-SYK-03 reached statistically significant reductions of paw volume, but only by day 28 . As for toxicological profile, MT-SYK-03 demonstrated the best survival rate ( $0 \%$ rats died) compared to sodium diclofenac (20\% rats died) and MTX (20\% and $70 \%$ rats died after 0.2 and $0.5 \mathrm{mg} / \mathrm{kg}$ administration, respectively, Table S23). All rats died from bleeding ulcerative lesions of the stomach and intestines, confirming known side effects of diclofenac and MTX and showing lack of this fall-out for MT-SYK-03.

MT-SYK-03 alleviates pain in MIA-induced OA in rats. The development of pain in OA is correlated with joint destruction but it can also be induced by more subtle changes or biochemical events without structural correlates ${ }^{46}$. Injection of sodium mono-iodoacetate (MIA) into rat joint is referred as a chronic pain model caused by cartilage degeneration ${ }^{46,51}$. The initial period of knee swelling in the MIA model associated with a transient synovial inflammation may correlate with early synovial inflammation in clinical setting that predicts development of $\mathrm{OA}$ in the $\mathrm{knee}^{46}$. Pain syndrome was assessed using three criteria: hind paws grip strength, mechanical allodynia and mechanical hyperalgesia. MT-SYK-03 in all doses showed trend toward restoration of hind paws grip strength; nalgesin and zoledronic acid, in turn, showed stable statistically significant improvements, but only on day 28 (Table S24). According to mechanical hyperalgesia measurements, prophylactic administration of MT-SYK-03 led to statistically significant increase of pain thresholds for both doses from 

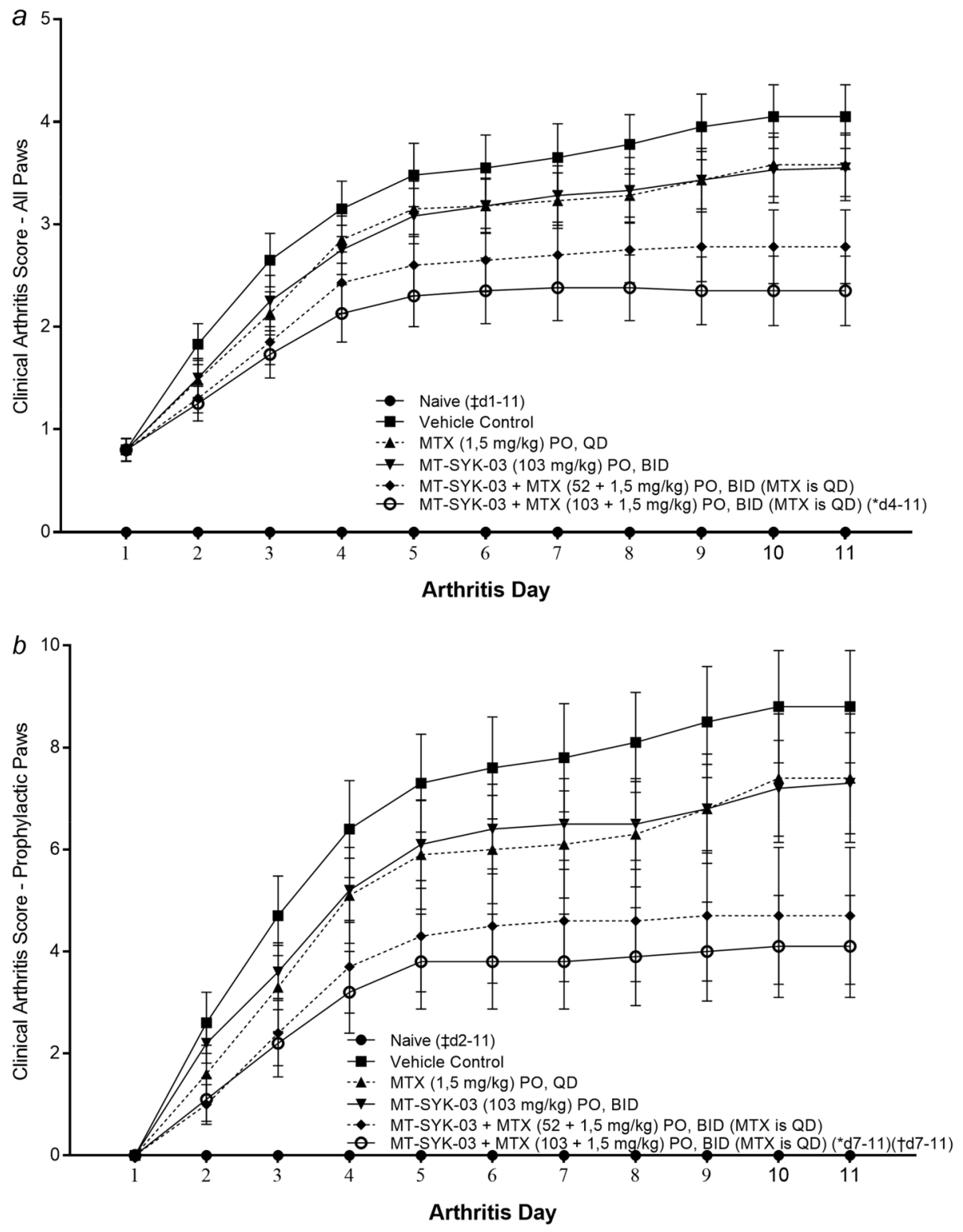

Figure 8. Effects of oral administration of MT-SYK-03 alone or in combination with MTX in murine CIA model. The clinical arthritis score, mean \pm SE ( $n=10$ for vehicle and treatment groups and 4 for naive group) for (a) all paws and (b) non-involved (prophylactic) paws for six groups of animals: Scores measured severity of inflammation from 0 (no inflammation) to 5 (severe inflammation). ${ }^{*} \mathrm{p}<0.05$ ANOVA to Vehicle Control, ${ }^{\dagger} \mathrm{p}<0.05$ ANOVA to MTX $(1.5 \mathrm{mg} / \mathrm{kg}),{ }^{\ddagger} \mathrm{p} \leq 0.05 t$-test to Vehicle Control.

day 14. In the therapeutic treatment regimen, a statistically significant improvement appeared only on day 28 for higher dose of MT-SYK-03. Both zoledronic acid and nalgesin demonstrated positive effects, but they were statistically significant only on days 21 and 28. Thus, prophylactic treatment with MT-SYK-03 has shown the best timing of onset (Table S25). According to mechanical allodynia measurements (Table S27), best efficacy of MTSYK-03 was reached with prophylactic treatment regimen: on day 14 pain threshold was elevated in all measurements, on days 21 and 28 -one and three hours after treatment. In the treatment regimen, positive effects of MT-SYK-03 administration became statistically significant on day 28 and only in the higher dose $-500 \mathrm{mg} / \mathrm{kg}$. Zoledronic acid and nalgesin increased the pain threshold, but their therapeutic effects were outplayed by those of MT-SYK-03 in the prophylactic treatment regime.

\section{Discussion}

The disease-modifying osteoarthritis drugs (DMOADs) being developed currently target only one of three main components of OA: articular cartilage damage, subchondral bone resorption, or synovium inflammation ${ }^{4,52,53}$. Despite the evidence of multiple phenotypes of OA, the data on how distinct phenotypes respond to current treatment is lacking ${ }^{4}$. In our study we tested the hypothesis whether selective inhibition of cSrc and SYK kinases by MT-SYK-03 can potentially affect all three pathogenetic components of OA. 


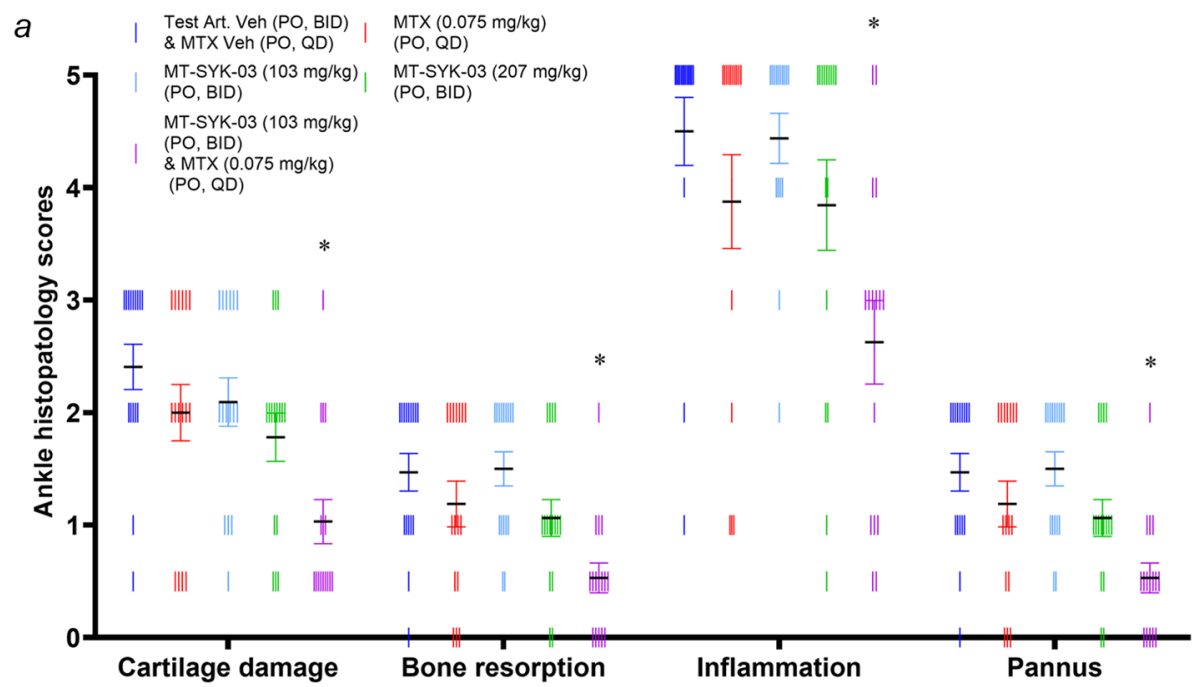

$b$
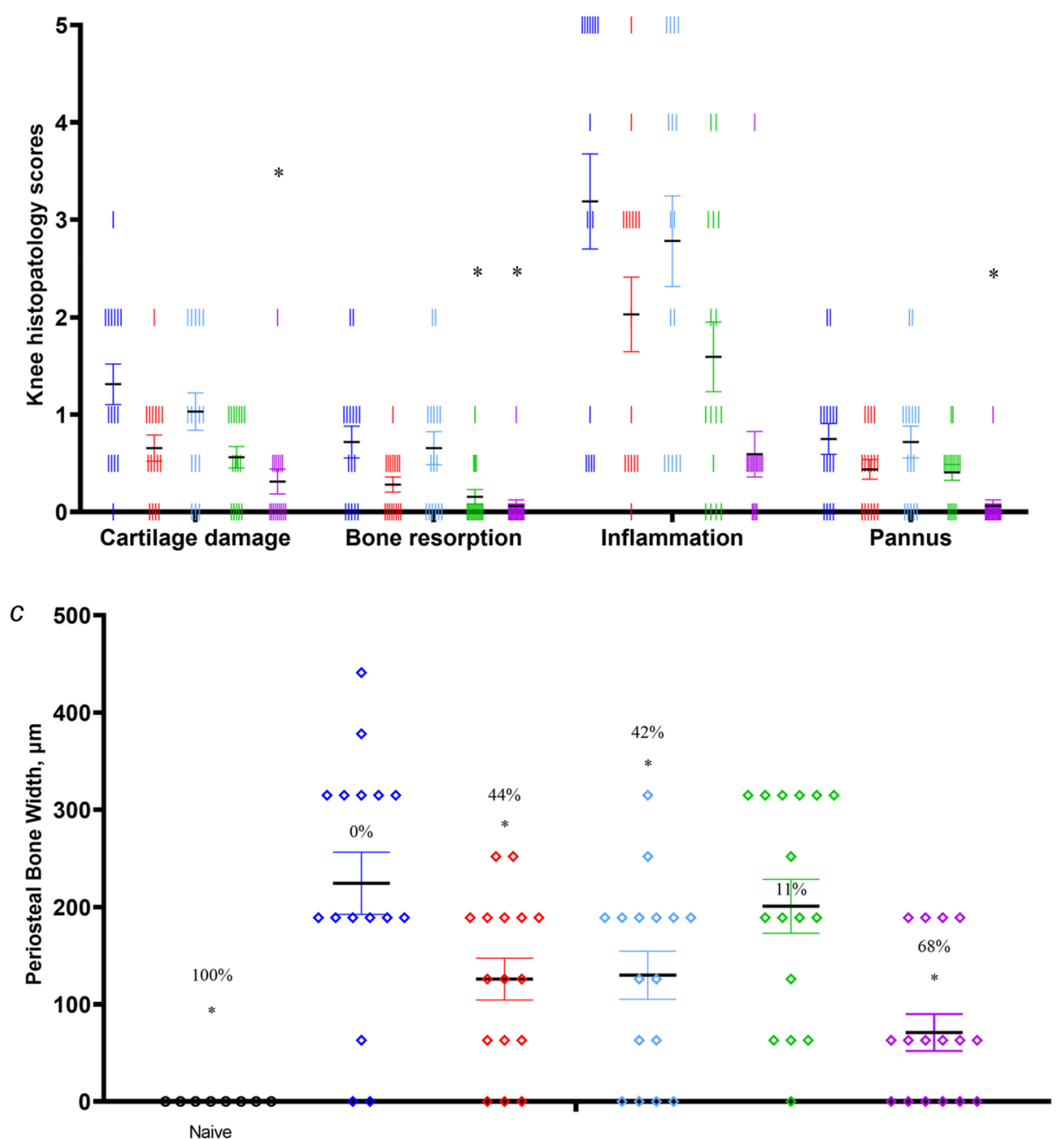

Figure 9. Effects of oral administration of MT-SYK-03 alone or in combination with MTX in 16 days rat semiestablished CIA on inflammation, pannus, cartilage damage and bone resorption in ankles (a) and knees (b) and periosteal bone width in knee joints (c). Individual data, Mean \pm SE $(n=8$ for treatment groups and 4 for naive group, 2 paws were assayed for each animal). ${ }^{*} \mathrm{p}<0.05$ ANOVA to Vehicle Control. 
MT-SYK-03 selectivity profile was compared with that of a known SYK kinase inhibitor R406 (tamatinib). The narrow therapeutic window for R406 was responsible for its discontinuation in rheumatoid arthritis ${ }^{54}$. A binding assay to profile MT-SYK-03 against 341 other protein kinases demonstrated that the molecule is highly selective. Complete selectivity toward cSrc is hard to reach due to its similarity to the related kinases ${ }^{55}$, but MT-SYK-03 is far more selective compared to R406 toward some of them (Lyn, Fyn, Hck, PDGFR, Lck, Fgr, Blk, Flt4, Ret, EphA1) and moderately inhibits (>54\% residual activity at $500 \mathrm{nM})$ the rest (BCR-Abl, c-Kit, EphA2, EphA3, EphA4, EphA5, EphA6, EphA7, EphA8, EphB2, EphB3, EphB4, EGFR, FGFR1-4, TIE2, Brk, Frk). Importantly, MT-SYK-03 did not inhibit FLT1 and KDR kinases inhibition of which was associated with hypertension ${ }^{56}$, diarrhea, nausea and increased transaminase ${ }^{57}$. Also, despite the high PO doses used in in vivo experiments, the average plasma concentration after administration in rats is relatively low and lies in 200-700 nM range thereby indicating the achievement of kinase selectivity in vivo. Interestingly, while plasma PK parameters confirmed achievability of effective concentrations in vivo, the drug's exposure to bone and cartilage tissues was found to be 3 times higher. Taken together with promising preclinical toxicology and a relatively selective kinase inhibition profile, there is a possibility of favorable safety of drug candidate in a clinical setting, which was recently confirmed by Phase 1 clinical study of MT-SYK-03 in healthy volunteers [to be published].

In vitro and in vivo studies were conducted to support cSrc and SYK-mediated biological action of MTSYK-03 and to check its effectivity in alleviation of OA symptoms: cartilage degradation, bone remodeling, inflammation, and pain. Antiresorptive and chondroprotective effects of MT-SYK-03 were demonstrated in osteoclast-mediated bone resorption and chondrocyte hypertrophic-like changes models in vitro and in surgically induced meniscal tear and collagen-induced arthritis models in vivo. Although it was hypothesized earlier that such effects may be associated with inhibiting other kinases (for example, osteoclastogenesis suppression was explained by MEK1, MAPKAPK2, PI3K or PKA inhibition ${ }^{12}$ ), MT-SYK-03 did not inhibit any from this list.

It should also be noted that some of in vivo models used to characterize MT-SYK-03, namely AIA and CIA, are well recognized as rheumatoid arthritis models and were used in this study to study features common for both RA and OA: inflamation ${ }^{58}$, immunity ${ }^{59,60}$, subchondral bone resorption ${ }^{22-24}$, and pannus ${ }^{25,26}$.

The role of SYK inhibition in the anti-inflammatory properties of MT-SYK-03 was tested in in vitro and in vivo models. In AIA model MT-SYK-03 was compared with methotrexate and diclofenac. Despite not being approved as an OA therapy, methotrexate efficacy was recently investigated in this indication ${ }^{61}$; some sources report its case studies in knee $\mathrm{OA}$ and erosive $\mathrm{OA}^{62-64}$. Administration of methotrexate and diclofenac was associated with severe adverse effects including lethality. On the contrary, MT-SYK-03 demonstrated anti-inflammatory activity without such adverse effects. MT-SYK-03 combined with MTX demonstrated efficacy in a setting where MTX alone was not effective ${ }^{65,66}$.

Current results demonstrate that MT-SYK-03 is a kinase inhibitor with a relatively selective profile and cSrc and SYK kinases among the main targets associated with OA. To our knowledge, this is the first compound which acts simultaneously on bone and cartilage metabolism and inflammation in the synovium and demonstrates disease-modifying ability (zoledronic acid that is approved only as an antiresorptive therapy showed low disease-modifying ability ${ }^{4}$; combined with severe adverse effects when administered intravenously ${ }^{67}$ ). The phase 2 clinical study of MT-SYK-03 in patients with painful OA is being planned.

Received: 5 April 2021; Accepted: 26 October 2021

Published online: 30 November 2021

\section{References}

1. Zhang, Y., Zhang, B., Wise, B., Niu, J. \& Zhu, Y. Statistical approaches to evaluating the effect of risk factors on the pain of knee osteoarthritis in longitudinal studies. Curr. Opin. Rheumatol. 21, 513-519 (2009).

2. Valdes, A. M. \& Spector, T. D. The genetic epidemiology of osteoarthritis. Curr. Opin. Rheumatol. 22, 139-143 (2010).

3. Zhang, Y. \& Jordan, J. M. Epidemiology of osteoarthritis. Clin. Geriatr. Med. 26, 355-369 (2010).

4. Oo, W. M., Yu, S. P. C., Daniel, M. S. \& Hunter, D. J. Disease-modifying drugs in osteoarthritis: Current understanding and future therapeutics. Expert Opin. Emerg. Drugs 23, 331-347 (2018).

5. Rainbow, R., Ren, W. \& Zeng, L. Inflammation and joint tissue interactions in OA: Implications for potential therapeutic approaches. Arthritis 2012, 1-8 (2012).

6. Liu-Bryan, R. \& Terkeltaub, R. Emerging regulators of the inflammatory process in osteoarthritis. Nat. Rev. Rheumatol. 11, 35-44 (2015).

7. Burr, D. B. \& Gallant, M. A. Bone remodelling in osteoarthritis. Nat. Rev. Rheumatol. 8, 665-673 (2012).

8. Houard, X., Goldring, M. B. \& Berenbaum, F. Homeostatic mechanisms in articular cartilage and role of inflammation in osteoarthritis. Curr. Rheumatol. Rep. 15, 6 (2013).

9. Nees, T. A. et al. Synovial cytokines significantly correlate with osteoarthritis-related knee pain and disability: Inflammatory mediators of potential clinical relevance. J. Clin. Med. 8, 1343 (2019).

10. Elemam, N. M., Hannawi, S. \& Maghazachi, A. A. Role of chemokines and chemokine receptors in rheumatoid arthritis. ImmunoTargets Ther. 9, 43-56 (2020).

11. Vandyke, K. et al. The tyrosine kinase inhibitor dasatinib dysregulates bone remodeling through inhibition of osteoclasts in vivo. J. Bone Miner. Res. 25, 1759-1770 (2010).

12. Metcalf, C. A., van Schravendijk, M. R., Dalgarno, D. C. \& Sawyer, T. K. Targeting protein kinases for bone disease: Discovery and development of Src inhibitors. Curr. Pharm. Des. 8, 2049-2075 (2002).

13. Miyazaki, T., Tanaka, S., Sanjay, A. \& Baron, R. The role of c-Src kinase in the regulation of osteoclast function. Mod. Rheumatol. 16, 68-74 (2006).

14. Zheng, L. Z. et al. Src siRNA prevents corticosteroid-associated osteoporosis in a rabbit model. Bone 83, 190-196 (2016).

15. Ghosh, D. \& Tsokos, G. C. Spleen tyrosine kinase: An Src family of non-receptor kinase has multiple functions and represents a valuable therapeutic target in the treatment of autoimmune and inflammatory diseases. Autoimmunity 43, 48-55 (2010).

16. Yi, Y.-S. et al. Functional roles of Syk in macrophage-mediated inflammatory responses. Mediators Inflamm. 2014, 1-12 (2014).

17. Geahlen, R. L. Getting Syk: Spleen tyrosine kinase as a therapeutic target. Trends Pharmacol. Sci. 35, 414-422 (2014). 
18. Coffey, G. et al. Specific inhibition of spleen tyrosine kinase suppresses leukocyte immune function and inflammation in animal models of rheumatoid arthritis. J. Pharmacol. Exp. Ther. 340, 350-359 (2012).

19. Braselmann, S. et al. R406, an orally available spleen tyrosine kinase inhibitor blocks fc receptor signaling and reduces immune complex-mediated inflammation. J. Pharmacol. Exp. Ther. 319, 998-1008 (2006).

20. Mocsai, A. et al. The immunomodulatory adapter proteins DAP12 and $\mathrm{Fc}$ receptor-chain $(\mathrm{FcR})$ regulate development of functional osteoclasts through the Syk tyrosine kinase. Proc. Natl. Acad. Sci. 101, 6158-6163 (2004).

21. Pine, P. R. et al. Inflammation and bone erosion are suppressed in models of rheumatoid arthritis following treatment with a novel Syk inhibitor. Clin. Immunol. 124, 244-257 (2007).

22. Chu, L. et al. Articular cartilage degradation and aberrant subchondral bone remodeling in patients with osteoarthritis and osteoporosis. J. Bone Miner. Res. 35, 505-515 (2020).

23. Chu, L. et al. Different subchondral trabecular bone microstructure and biomechanical properties between developmental dysplasia of the hip and primary osteoarthritis. J. Orthop. Transl. 22, 50-57 (2020).

24. Zhou, X., Cao, H., Yuan, Y. \& Wu, W. Biochemical signals mediate the crosstalk between cartilage and bone in osteoarthritis. BioMed Res. Int. 2020, 1-8 (2020).

25. Chen, Y. et al. Pannus does not occur only in rheumatoid arthritis: A pathological observation of pannus of knee osteoarthritis. Nan Fang Yi Ke Da Xue Xue Bao 39, 747-750 (2019).

26. Yuan, G.-H. et al. Characterization of cells from pannus-like tissue over articular cartilage of advanced osteoarthritis. Osteoarthritis Cartilage 12, 38-45 (2004)

27. Zeifman, A. A. et al. Rational design and synthesis of novel Syk-kinase inhibitors. Mendeleev Commun. 22, 73-74 (2012).

28. Rakitina, T. V., Yudkina, O. V., Smirnova, E. V. \& Lipkin, A. V. Protein tyrosine kinase panel as a tool for anticancer drug design. Acta Naturae 1, 84-88 (2009).

29. Gao, Y. et al. A broad activity screen in support of a chemogenomic map for kinase signalling research and drug discovery. Biochem. J. 451, 313-328 (2013).

30. Pfaffl, M. W., Horgan, G. W. \& Dempfle, L. Relative expression software tool (REST@) for group-wise comparison and statistical analysis of relative expression results in real-time PCR. Nucleic Acids Res. 30, e36 (2002).

31. Janusz, M. J. et al. Induction of osteoarthritis in the rat by surgical tear of the meniscus: Inhibition of joint damage by a matrix metalloproteinase inhibitor. Osteoarthr. Cartil. 10, 785-791 (2002).

32. Bove, S. E. et al. Weight bearing as a measure of disease progression and efficacy of anti-inflammatory compounds in a model of monosodium iodoacetate-induced osteoarthritis. Osteoarthr. Cartil. 11, 821-830 (2003).

33. Leitinger, B. Molecular analysis of collagen binding by the human discoidin domain receptors, DDR1 and DDR2. Identification of collagen binding sites in DDR2. J. Biol. Chem. 278, 16761-16769 (2003).

34. Kerroch, M. et al. Protective effects of genetic inhibition of Discoidin Domain Receptor 1 in experimental renal disease. Sci. Rep. 6, 21262 (2016).

35. Fu, H.-L. et al. Discoidin domain receptors: Unique receptor tyrosine kinases in collagen-mediated signaling. J. Biol. Chem. 288, 7430-7437 (2013).

36. Karimaian, A., Majidinia, M., Bannazadeh Baghi, H. \& Yousefi, B. The crosstalk between Wnt/ $\beta$-catenin signaling pathway with DNA damage response and oxidative stress: Implications in cancer therapy. DNA Repair 51, 14-19 (2017).

37. Schminke, B. et al. A discoidin domain receptor 1 knock-out mouse as a novel model for osteoarthritis of the temporomandibular joint. Cell. Mol. Life Sci. CMLS 71, 1081-1096 (2014).

38. Han, T., Mignatti, P., Abramson, S. B. \& Attur, M. Periostin interaction with discoidin domain receptor-1 (DDR1) promotes cartilage degeneration. PLoS ONE 15, e0231501 (2020).

39. Paradowska-Gorycka, A. \& Stypinska, B. MicroRNAs in rheumatoid arthritis: From pathogenesis to clinical utility. In New Developments in the Pathogenesis of Rheumatoid Arthritis (ed. Sakkas, L. I.) (InTech, 2017). https://doi.org/10.5772/67320.

40. Yan, B., Li, J. \& Zhang, L. Identification of B cells participated in the mechanism of postmenopausal women osteoporosis using microarray analysis. Int. J. Clin. Exp. Med. 8, 1027-1034 (2015).

41. Zhang, H. et al. Influence of BLK polymorphisms on the risk of rheumatoid arthritis. Mol. Biol. Rep. 39, 9965-9970 (2012).

42. Kleinau, S., Martinsson, P. \& Heyman, B. Induction and suppression of collagen-induced arthritis is dependent on distinct Fc $\gamma$ receptors. J. Exp. Med. 191, 1611-1616 (2000).

43. Kubota, E. Interleukin $1 \mathrm{p}$ and stromelysin (MMP3) activity of synovial fluid as possible markers of osteoarthritis in the temporomandibular joint. J. Oral Maxillofac. Surg. 55, 20-27 (1997).

44. Laufer, S., Greim, C. \& Bertsche, T. An in-vitro screening assay for the detection of inhibitors of proinflammatory cytokine synthesis: A useful tool for the development of new antiarthritic and disease modifying drugs. Osteoarthr. Cartil. 10, 961-967 (2002).

45. Gerwin, N., Bendele, A. M., Glasson, S. \& Carlson, C. S. The OARSI histopathology initiative-recommendations for histological assessments of osteoarthritis in the rat. Osteoarthr. Cartil. 18, S24-S34 (2010).

46. Fernihough, J. et al. Pain related behaviour in two models of osteoarthritis in the rat knee. Pain 112, 83-93 (2004).

47. Loffredo, F. S. et al. Targeted delivery to cartilage is critical for in vivo efficacy of insulin-like growth factor 1 in a rat model of osteoarthritis. Arthritis Rheumatol. 66, 1247-1255 (2014).

48. Williams, R. O. Models of rheumatoid arthritis. In Animal Models of T Cell-Mediated Skin Diseases 89-117 (Springer Berlin Heidelberg, 2005). https://doi.org/10.1007/3-540-26811-1_5.

49. Weinblatt, M. E. Methotrexate in rheumatoid arthritis: A quarter century of development. Trans. Am. Clin. Climatol. Assoc. 124, 16-25 (2013).

50. Weinblatt, M. E. Methotrexate: Who would have predicted its importance in rheumatoid arthritis?. Arthritis Res. Ther. 20, 103 (2018).

51. Guzman, R. E., Evans, M. G., Bove, S., Morenko, B. \& Kilgore, K. Mono-iodoacetate-induced histologic changes in subchondral bone and articular cartilage of rat femorotibial joints: An animal model of osteoarthritis. Toxicol. Pathol. 31, 619-624 (2003).

52. Karsdal, M. A. et al. Disease-modifying treatments for osteoarthritis (DMOADs) of the knee and hip: Lessons learned from failures and opportunities for the future. Osteoarthr. Cartil. 24, 2013-2021 (2016).

53. Wei, Y. \& Bai, L. Recent advances in the understanding of molecular mechanisms of cartilage degeneration, synovitis and subchondral bone changes in osteoarthritis. Connect. Tissue Res. 57, 245-261 (2016).

54. Genovese, M. C. et al. A phase III, multicenter, randomized, double-blind, placebo-controlled, parallel-group study of 2 dosing regimens of fostamatinib in patients with rheumatoid arthritis with an inadequate response to a tumor necrosis factor- $\alpha$ antagonist. J. Rheumatol. 41, 2120-2128 (2014).

55. Sousa, S. \& Clézardin, P. Bone-targeted therapies in cancer-induced bone disease. Calcif. Tissue Int. 102, 227-250 (2018).

56. Rolf, M. G. et al. In vitro pharmacological profiling of R406 identifies molecular targets underlying the clinical effects of fostamatinib. Pharmacol. Res. Perspect. 3, e00175 (2015).

57. Bussel, J. et al. Fostamatinib for the treatment of adult persistent and chronic immune thrombocytopenia: Results of two phase 3, randomized, placebo-controlled trials. Am. J. Hematol. 93, 921-930 (2018).

58. Chow, Y. Y. \& Chin, K.-Y. The role of inflammation in the pathogenesis of osteoarthritis. Mediators Inflamm. 2020, 1-19 (2020).

59. Lopes, E. B. P., Filiberti, A., Husain, S. A. \& Humphrey, M. B. Immune contributions to osteoarthritis. Curr. Osteoporos. Rep. 15, 593-600 (2017). 
60. Kalaitzoglou, E., Griffin, T. M. \& Humphrey, M. B. Innate immune responses and osteoarthritis. Curr. Rheumatol. Rep. 19, 45 (2017).

61. Enteshari-Moghaddam, A., Isazadehfar, K., Habibzadeh, A. \& Hemmati, M. Efficacy of methotrexate on pain severity reduction and improvement of quality of life in patients with moderate to severe knee osteoarthritis. Anesthesiol. Pain Med. 9, 89990 (2019).

62. Wenham, C. Y. J. et al. Methotrexate for pain relief in knee osteoarthritis: An open-label study. Rheumatology 52, 888-892 (2013).

63. de Holanda, H. T., Pollak, D. F. \& Pucinelli, M. L. C. Baixa dose de methotrexate comparado a placebo em osteoartrite de joelho. Rev. Bras. Reumatol. 47, 334-340 (2007).

64. Kingsbury, S. R. et al. Pain reduction with oral methotrexate in knee osteoarthritis, a pragmatic phase iii trial of treatment effectiveness (PROMOTE): Study protocol for a randomized controlled trial. Trials 16, 77 (2015).

65. Bove, S. E. et al. Surgically induced osteoarthritis in the rat results in the development of both osteoarthritis-like joint pain and secondary hyperalgesia. Osteoarthr. Cartil. 14, 1041-1048 (2006).

66. Buijs, T., Kuijpers, C. H. J. \& van der Pluijm, G. Targeted therapy options for treatment of bone metastases beyond bisphosphonates. Curr. Pharm. Des. 16, 3015-3027 (2010).

67. White, S. L., Jacob, A., Gregson, C. \& Bhalla, A. Severe polyarthritis secondary to zolendronic acid: A case report and literature review. Clin. Cases Miner. Bone Metab. Off. J. Ital. Soc. Osteoporos. Miner. Metab. Skelet. Dis. 12, 69-74 (2015).

\section{Author contributions}

N.F.N., O.V.S. and G.G.C. planned and supervised the experiments. I.Y.T. synthesized the inhibitor. N.F.N., M.V.P., V.S.S., O.V.S., and G.G.C. analysed and interpreted the data. N.F.N., M.V.P., V.S.S., O.V.S., and G.G.C. wrote the manuscript. All authors reviewed the manuscript.

\section{Competing interests}

The authors declare no competing interests.

\section{Additional information}

Supplementary Information The online version contains supplementary material available at https://doi.org/ 10.1038/s41598-021-02568-6.

Correspondence and requests for materials should be addressed to I.Y.T. or V.S.S.

Reprints and permissions information is available at www.nature.com/reprints.

Publisher's note Springer Nature remains neutral with regard to jurisdictional claims in published maps and institutional affiliations.

(c) (i) Open Access This article is licensed under a Creative Commons Attribution 4.0 International License, which permits use, sharing, adaptation, distribution and reproduction in any medium or format, as long as you give appropriate credit to the original author(s) and the source, provide a link to the Creative Commons licence, and indicate if changes were made. The images or other third party material in this article are included in the article's Creative Commons licence, unless indicated otherwise in a credit line to the material. If material is not included in the article's Creative Commons licence and your intended use is not permitted by statutory regulation or exceeds the permitted use, you will need to obtain permission directly from the copyright holder. To view a copy of this licence, visit http://creativecommons.org/licenses/by/4.0/.

(c) The Author(s) 2021, corrected publication 2022 